\title{
Avian blood parasites in an endangered columbid: Leucocytozoon marchouxi in the Mauritian Pink Pigeon Columba mayeri
}

\author{
N. BUNBURY 1,3*, E. BARTON ${ }^{2}$, C. G. JONES ${ }^{3,5}$, A. G. GREENWOOD ${ }^{4}$, K. M. TYLER ${ }^{2}$ \\ and D. J. BELL ${ }^{1}$ \\ ${ }^{1}$ Centre for Ecology, Evolution and Conservation, University of East Anglia, UK \\ ${ }^{2}$ School of Medicine, Health Policy and Practice, University of East Anglia, UK \\ ${ }^{3}$ Mauritian Wildlife Foundation, Grannum Road, Vacoas, Mauritius \\ ${ }^{4}$ International Zoo Veterinary Group, Keighley Business Centre, South Street, Keighley, W. Yorkshire BD21 1AG, UK \\ ${ }^{5}$ Durrell Wildlife Conservation Trust, Les Augrès Manor, Trinity, Fersey FE3 5BP, Channel Islands, UK
}

(Received 23 Fanuary 2006; revised 13 Fune 2006; accepted 2 November)

\section{SUMMARY}

There is increasing evidence that pathogens can play a significant role in species decline. This study of a complete freeliving species reveals a cost of blood parasitism to an endangered host, the Pink Pigeon Columba mayeri, endemic to Mauritius. We investigated the prevalence and effect of infection of the blood parasite, Leucocytozoon marchouxi, in the free-living Pink Pigeon population. Overall, L. marchouxi infection prevalence detected was $18 \cdot 3 \%$. Juveniles were more likely to be infected than older birds and there was geographical variation in infection prevalence. Survival of birds infected with L. marchouxi was lower than that of uninfected birds to 90 days post-sampling. This study suggests that while common haematozoa are well tolerated in healthy adults, these parasites may have greater pathogenic potential in susceptible juveniles. The study is unusual given its completeness of species sampling (96\%) within a short time-period, the accurate host age data, and its focus on blood parasites in a threatened bird species. Species for which long-term life-history data are available for every individual serve as valuable models for dissecting the contribution of particular pathogens to species decline.

Key words: avian haematozoa, infection prevalence, survivorship, age structure, conservation, avian endemic.

\section{INTRODUCTION}

Determining the link between a micro-organism and pathogenicity can be difficult, particularly in situations where Koch's postulates cannot be fulfilled. This is a critical issue in medical and veterinary science, but also in conservation biology where pathogens are increasingly recognized as playing a significant role in biodiversity decline (McCallum and Dobson, 1995 ; Daszak et al. 2000; Deem et al. 2001). Closed and managed populations are valuable for elucidating such connections because every individual can be examined at a given time-point and the presence of a microbe can be closely matched with the life-history and health status of the individual. The Pink Pigeon Columba mayeri, one of the rarest Columbids in the world, has been recovered from approximately 12 birds in the wild in the early 1990s (Swinnerton, 2001). The species survives today in a closely monitored and managed, insular population of over 350 individuals on the Indian

* Corresponding author: Langackerstrasse 50, 8057 Zürich, Switzerland. E-mail: N.Bunbury@uea.ac.uk
Ocean island of Mauritius, making it a valuable model in which to study the impact of parasites on hosts.

Avian haematozoa have been recorded in approximately $68 \%$ of all bird species examined (Atkinson and van Riper, 1991). Studies on avian haematozoa have underpinned several evolutionary and ecological theories of recent decades (e.g. Ricklefs, 1992; Tella, 2002) including the parasitemediated sexual selection hypothesis proposed by Hamilton and Zuk (1982). The key conjecture of most of these theories is that haematozoa are costly to their hosts. Pathogenic effects on domestic and captive avian populations are well-documented (Fallis and Bennett, 1966; Herman et al. 1970; Bennett et al. 1993). However, despite occasional reported negative effects on host condition and reproductive success (e.g. Ots and Horak, 1998; Dawson and Bortolotti, 2000; Merino et al. 2000), most studies have not demonstrated significant direct pathogenic effects of haematozoa on host survival in wild avian individuals, much less populations (e.g. Ashford et al. 1990; Weatherhead and Bennett, 1992; Bennett et al. 1993; Davidar and Morton, 1993; Shutler et al. 1996; Schrader et al. 2003). 
Comparative studies of blood parasite infection rates across and within species present methodological problems; non-circulating chronic infections are difficult to detect in blood smears (Weatherhead and Bennett, 1991; Schrader et al. 2003), and both temporal and geographical variation in prevalence can be marked even within a single host population (Weatherhead and Bennett, 1991, 1992; Merila et al. 1995; Sol et al. 2000; Krone et al. 2001; Schrader et al. 2003). Simultaneous sampling of a large number of individuals in several different localities across a species' range has been recommended to overcome these problems (Weatherhead and Bennett, 1991, 1992; Merila et al. 1995).

Here, we investigate a vector-borne blood parasite in the entire free-living population of the endangered Pink Pigeon within a relatively short time-period of 2 months. Several parasites have been previously identified in the Pink Pigeon; most frequently the flagellate protozoan Trichomonas gallinae and the haematozoan Leucocytozoon marchouxi. Both species are common in the Columbidae throughout the geographical distribution of the family. However, there are no long-term data available to determine whether these parasites are native to Mauritius and the Pink Pigeon or were introduced with one or more exotic avian species now present on the island.

Leucocytozoon marchouxi is most commonly found in the Columbiformes, in which it is rarely known to be pathogenic (Peirce et al. 1997; Valkiūnas, 2005). The species was first described in the Pink Pigeon in 1977 and was later highlighted as a potential threat to the species' continued recovery (Peirce et al. 1977, 1997). Leucocytozoids are, with one known exception, transmitted by Simuliid blackflies and the only Simuliid species known from Mauritius, Simulium ruficorne, has been proposed as the probable vector of L. marchouxi (Peirce et al. 1977, 1997).

In this study, we focus on the distribution and prevalence of L. marchouxi in the Pink Pigeon and its impact on host survivorship. We collected blood smears and crop swabs from free-living Pink Pigeons over a 2 -month period. A long-term (17 year) dataset on life-history parameters in all individuals of the species enabled analysis of parasite prevalence with respect to several demographic parameters including age, sex and subpopulation. In analyses of parasitaemias at different life-history stages of wild avian hosts, it is usually only possible to categorize age groups into juveniles and adults, or hatching year, second year and post-second year birds (e.g. Weatherhead and Bennett, 1991, 1992; Allander and Bennett, 1994; Seutin, 1994; Deviche, Greiner and Manteca, 2001; Sol et al. 2003). However, in our study, it was possible to compare prevalence of blood parasites across annual age classes, since the age of all Pink Pigeons is known accurately to month of hatching. The small population size of the Pink Pigeon, combined with the fact that all free-living

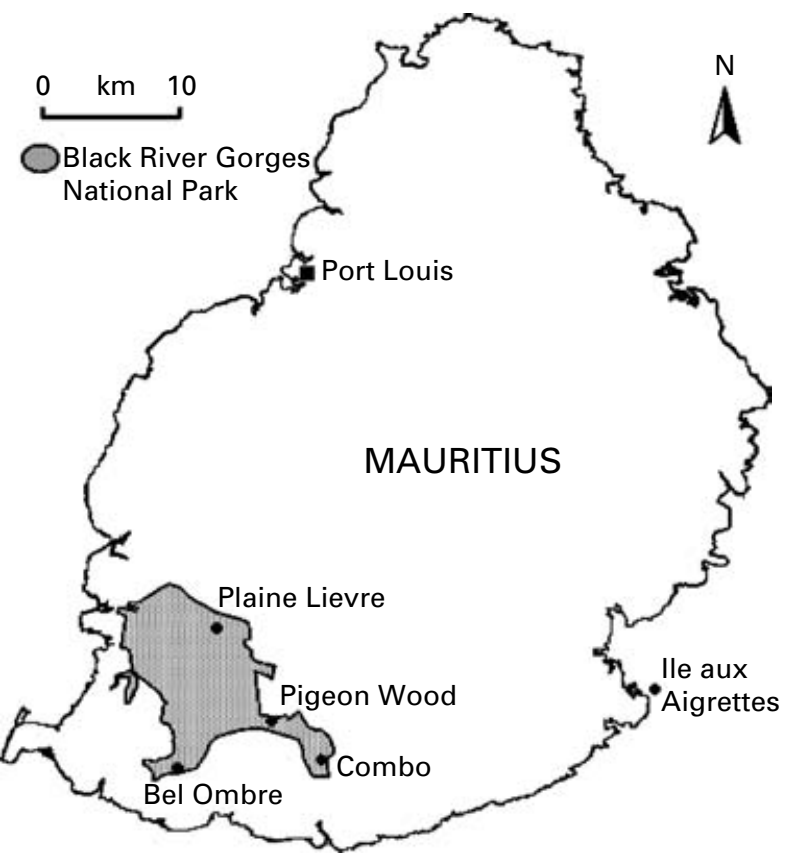

Fig. 1. Map of Mauritius showing the location of the five Pink Pigeon subpopulations and the National Park.

individuals of the species can be captured, facilitated the comprehensive sampling and monitoring required for this study. Furthermore, the daily monitoring of survival of all individuals in the population permitted analysis of post-sampling survivorship of birds to different end-points.

This paper examines how the prevalence of detectable L. marchouxi infection varied with Pink Pigeon age, sex, body condition and subpopulation within a 2 -month period. We also test the prediction that haematozoan infection is detrimental to host survival by comparing survival probabilities among birds testing positive and negative for L. marchouxi.

\section{MATERIALS AND METHODS}

There are 5 distinct Pink Pigeon subpopulations, 4 of which are in the Black River Gorges National Park on mainland Mauritius and the fifth on the 25 hectare coral islet, Ile aux Aigrettes (Fig. 1). The study was carried out in September and October 2003 as part of a larger investigation into Pink Pigeon parasites.

All Pink Pigeons had been previously ringed as juveniles as part of the species recovery programme run by the Mauritian Wildlife Foundation and the National Parks and Conservation Service of Mauritius. The hatch date of each individual was estimated to the nearest month and birds sampled $(n=328)$ ranged from 3 months to14 years of age. Sex of all pigeons is recorded once individuals reach sexual maturity at approximately 6 months old, when sex is determined on the basis of reproductive behaviours. Pigeons were trapped in field aviaries 
containing supplementary food stations and captured with padded hand-held nets. Body mass was recorded to the nearest $5 \mathrm{~g}$; tarsus length, culmen-gape, culmen-skull and culmen-feathers were measured to the nearest $0.1 \mathrm{~mm}$ and the length of the right wing and central rectrix to the nearest $\mathrm{mm}$. Two thin blood smears were obtained for each bird from a drop of blood collected from a clipped outermost claw. All birds were released immediately after sample collection and individuals were only sampled once in this 2-month period. Blood slides were airdried and fixed in absolute methanol for $3 \mathrm{~min}$ immediately after sample collection, and later stained with Giemsa's stain buffered to $\mathrm{pH} 7 \cdot 2$ for $45 \mathrm{~min}$. Slides were marked with a reference number unrelated to bird identity, so that parasite scoring was conducted blind. Both blood smears from each bird were examined microscopically for the presence of blood parasites. Entire smears were scanned at $\times 400$, and presence or absence of haematozoa was recorded. Intensity of parasitaemia was not quantified because many detectable (patent) infections occurred at very low densities (sometimes 1 parasite per slide) in the blood. Birds were recorded as either infected (those with patent parasitaemias i.e. parasite(s) detected on at least 1 smear) or uninfected (no parasites detected on either smear). It is not possible to differentiate between uninfected birds and those with latent infections so use of the term 'uninfected' here, refers to birds in which no patent parasitaemia was detected. The term 'prevalence' is used here to describe the proportion of birds exhibiting patent parasitaemia. Post-sampling survival of all individuals was monitored.

\section{Data analysis}

Birds were defined as originating from the subpopulation in which they either hatched or were released into (for captive-bred birds). Age was grouped by year but, as sample size decreased with increasing age, 5- and 6-year-olds were grouped together and the oldest category included birds aged 7 years and older. Differences in infection prevalence across subpopulations, age groups and sexes were analysed using Pearson's Chi-square tests or Fisher's Exact test for small sample sizes. To obtain an index of condition independent of body size, we carried out a Principal Component Analysis (PCA) with the 6 linear morphometric measurements and used the first component as an index of body size. This was regressed against body mass to control for the effect of structural size and the resulting residuals were used as a measure of condition. We analysed condition of males and females separately. We used logistic regression to determine the relative importance of different variables on the probability of infection with L. marchouxi. Age, subpopulation and sex were entered as factors in one analysis and
L. marchouxi infection status (infected/uninfected) entered as the response variable. We used indicator contrast for the categorical variables which produces estimates comparing each group to the reference group. We checked for multi-collinearity between explanatory variables. Body condition was analysed in a separate logistic regression because we did not have morphometric data for all birds. Post-sampling survival was analysed using Kaplan-Meier estimates (Kaplan and Meier, 1958) with day of sampling as day zero. Statistical analysis was carried out in SPSS v. 12.01 for Windows and all statistical tests were two-tailed.

\section{RESULTS}

We collected blood smears from 328 of the total 342 free-living Pink Pigeons $(95.9 \%$ of the total wild population of this species) comprising 183 males, 143 females and 2 birds of unknown sex, which died before reaching sexual maturity. We sampled 98 birds ( $97 \%$ of subpopulation) at Plaine Lievre, 28 $(96.5 \%$ plus an additional seven dispersers from Combo) at Pigeon Wood, $63(100 \%)$ at Bel Ombre, $77(87 \cdot 5 \%)$ at Ile aux Aigrettes and $55(88.7 \%)$ at Combo, although $100 \%$ of the Combo subpopulation was screened across sites. Overall, L. marchouxi infection was detected in 60 birds $(18 \cdot 3 \%)$ and 6 individuals were infected with microfilariae $(1 \cdot 8 \%)$. One trypanosome, putatively identified as Trypanosoma corvi, was observed in a single apparently healthy, adult male from the Combo subpopulation, in which no other blood parasites were detected. Five birds were co-infected with $L$. marchouxi and microfilariae $(1 \cdot 5 \%)$.

Prevalence of L. marchouxi differed significantly across subpopulations $\left(\chi^{2}=20 \cdot 81, \quad P=<0 \cdot 001\right.$, D.F. $=4)$ with Combo showing the highest (32\%), and Pigeon Wood showing the lowest (5\%) prevalence. The numbers of birds infected with $L$. marchouxi in different subpopulations were 18/98 at Plaine Lievre; $2 / 35$ at Pigeon Wood; 7/63 at Bel Ombre; $12 / 77$ at Ile aux Aigrettes and $21 / 55$ at Combo (Fig. 2A). Five of the 6 individuals infected with microfilariae were sampled at Combo and the sixth was sampled at Pigeon Wood, but it had recently dispersed there from the Combo subpopulation. Due to the small sample sizes involved, the microfilariae infections are not discussed further. Twenty birds were screened at sites other than their site of origin (dispersers) and the majority of these dispersed between Pigeon Wood and Combo; 10 from Combo to Pigeon Wood and 4 the opposite direction. The mean age of these dispersers was $1 \cdot 85 \pm 0 \cdot 31$ s.E. years.

Prevalence also differed between age classes $\left(\chi^{2}=30 \cdot 26, P=<0 \cdot 001\right.$, D.F. $=6$; Fig. $\left.2 B\right)$ with the youngest age class $(<1$ year) showing significantly higher prevalence than all older year groups. To 
A

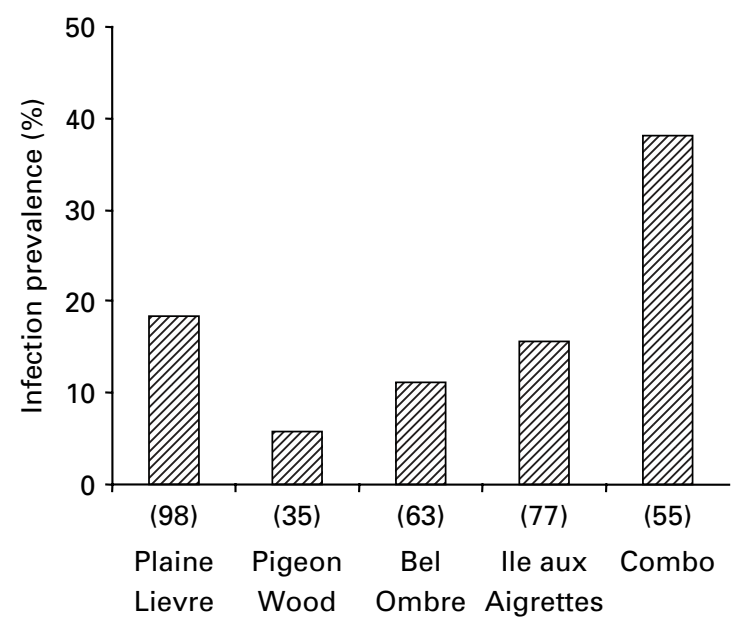

B

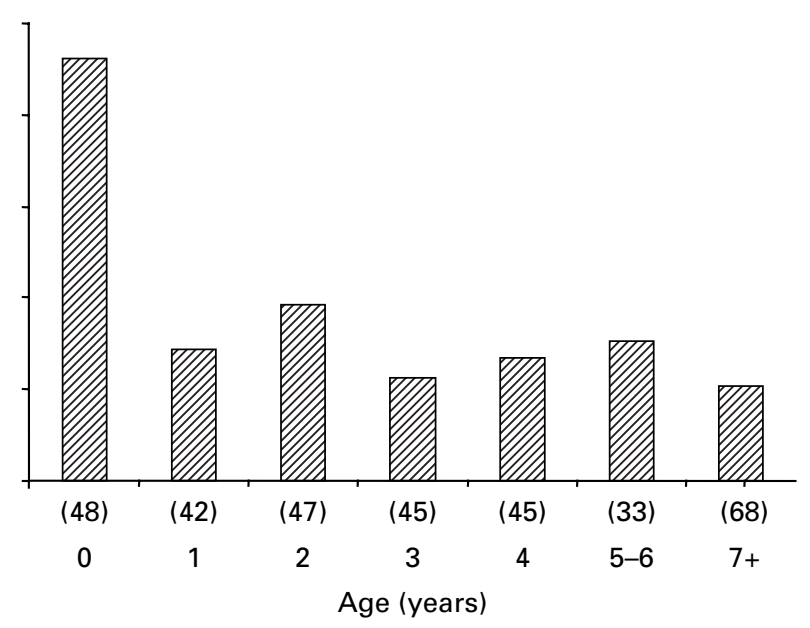

Fig. 2. Prevalence of infection with Leucocytozoon marchouxi in Pink Pigeons in relation to (A) subpopulation sampled and (B) age (in years). Prevalence was measured as the percentage of birds in each group with detectable infections from blood smears. Numbers in parentheses refer to sample size.

exclude the possibility that the high prevalence detected in the Combo subpopulation was confounding this result, we repeated the age analysis excluding the Combo data. Sample sizes were too small to use the same age categories but when data from the 4 other subpopulations were pooled, infection prevalence was again significantly higher in young $(<1$ year) compared to older ( $\geqslant 1$ year) age classes $\left(\chi^{2}=15 \cdot 19, P<0 \cdot 01\right.$, D.F. $\left.=1\right)$. When birds less than 1 year old were excluded from the analysis, there was no significant difference in L. marchouxi prevalence among other age classes $\left(\chi^{2}=2 \cdot 19, P=0 \cdot 82\right.$, D.F. $=5$ ).

There was no significant difference in L. marchouxi infection prevalence between males and females (males $32 / 183=17 \cdot 5 \%$; females $27 / 143=18.9 \%$; $\left.\chi^{2}=0 \cdot 105, P=0 \cdot 75\right)$.

Logistic regression provided further support for the above results. This revealed age and subpopulation to be significant predictor variables for L. marchouxi infection status (age: $P=0.004$, $\chi^{2}=8 \cdot 37$; subpopulation: $\left.\chi^{2}=14 \cdot 29, P=0 \cdot 006\right)$ but not $\operatorname{sex}\left(\chi^{2}=0.006, P=0.94\right)$, although the overall explanatory power of this model was low (Nagelkerke $\mathrm{R}^{2}=0 \cdot 128$ ). No collinearity was found between explanatory variables. In a separate analysis, body condition did not emerge as a significant predictor variable for $L$. marchouxi infection status $\left(\chi^{2}=0 \cdot 94, P=0 \cdot 33\right)$.

In the 3 months post-sampling, the mortality rate was $6.7 \%$ in $L$. marchouxi-infected birds compared to $1.9 \%$ in uninfected birds. Similar figures to 12 months post-sampling were $20.6 \%$ and $12 \%$ respectively in infected and uninfected birds. Infected birds were significantly less likely to survive to 90 days post-sampling than uninfected birds ( $\log$ rank $=4 \cdot 30, P=0.038$, Fig. 3) and although the difference in survival probabilities of infected and

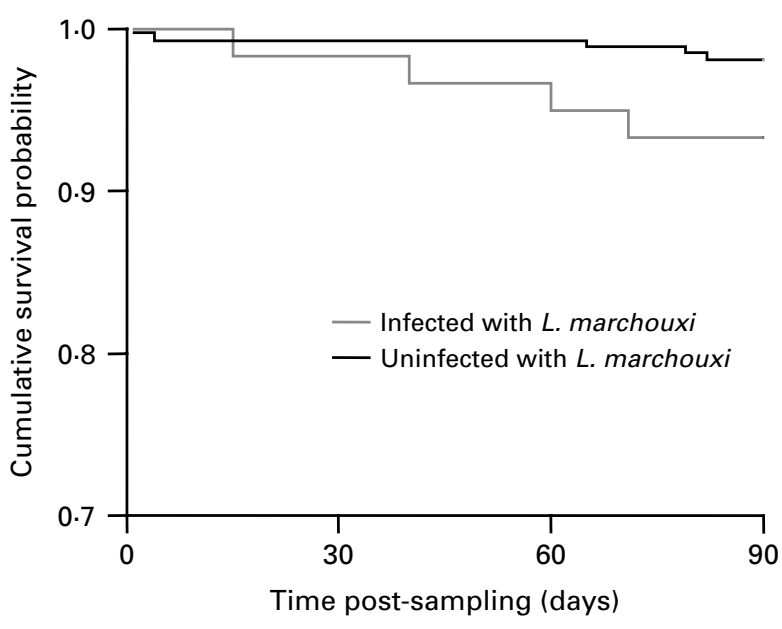

Fig. 3. Cumulative survival of Leucocytozoon marchouxi infected and uninfected Pink Pigeons to 90 days post-sampling (Kaplan-Meier survival plot, $P=0 \cdot 038$ ).

uninfected birds persisted to at least 1 year postsampling, it became increasingly less marked and was not statistically significant to 1 year $(\log \operatorname{rank}=1 \cdot 49$, $P=0 \cdot 22$ ). Of the 9 birds that died within 90 days of sampling, 4 were infected with $L$. marchouxi. Five of the 9 deaths were birds less than 1 year old; 3 of these $(60 \%)$ were infected with $L$. marchouxi. Despite screening the whole population, the low mortality rate precluded more detailed comparison of survival of infected and uninfected birds within age classes.

\section{DISCUSSION}

Accurate assessments of age structure in wild populations are rare, due to difficulties in sampling and estimating adult age. This study is therefore unusual with respect to its accurate age breakdown of an entire population. Our finding of a higher 
probability of infection in younger pigeons $(<1$ year old) compared to those aged 1 year and older confirms results of partial screening of the same population earlier in the species recovery programme (Swinnerton et al. 2005) but contrasts with the pattern commonly seen in other avian species (e.g. Davidar and Morton, 1993; Seutin, 1994; Merila et al. 1995; Sol et al. 2000; Krone et al. 2001 ; Sanz et al. 2001). Our negative age-prevalence relationship indicates that individuals are infected at an early age, and this may be because older birds have acquired immunity due to high intensity infections as young birds. Alternatively, it may reflect age differences in exposure to vectors, although this hypothesis was rejected by Sol et al. (2000) in their study of Haemoproteus infection in feral pigeons. We found no significant difference in infection prevalence between any age classes of 1 year and over. Most studies split populations into 2 or 3 age classes and few have been able to investigate age differences in prevalence with this degree of accuracy. We found no evidence of an age-related pattern to dispersal between Pink Pigeon subpopulations but analysis of a larger number of dispersers over a longer time period is required to confirm this.

A preliminary study of L. marchouxi in wild Pink Pigeons found a higher overall prevalence of $30 \%$ and no significant differences between subpopulations (Swinnerton et al. 2005). The latter result contrasts with our finding that infection prevalence varies significantly $(5 \cdot 7-38 \cdot 2 \%)$ across subpopulations when sampled within a 2 -month time-period. Swinnerton et al. (2005) estimated prevalence based on blood smears collected over different years and seasons. However, estimates of infection prevalence across years and/or seasons are of limited value with parasites such as L. marchouxi, which show seasonal latency within the host. Recrudescence of haematozoan infection may be triggered by host reproduction; avian hosts in the northern hemisphere show a Spring relapse of Leucocytozoon parasitaemia (e.g. Ashford et al. 1990; Weatherhead and Bennett, 1991; Norris et al. 1994; Dawson and Bortolotti, 1999; Krone et al. 2001), coinciding with both host breeding and vector emergence (Rintamaki et al. 1999; Deviche et al. 2001; Schrader et al. 2003). It has therefore been recommended that sampling for blood parasites be conducted in the mid-portion of the breeding season (Weatherhead and Bennett, 1991) which corresponds with the 2-month (Sept.Oct.) screening period used in the present study.

Geographical variation in infection prevalence has been attributed to differential exposure to key vector species (e.g. Sol et al. 2000). However, in Mauritius, suitable habitat for simuliid vectors (perennial streams and rivers and temperate, humid climate) occurs at sites of all Pink Pigeon subpopulations except on Ile aux Aigrettes, where there is no natural freshwater. Blackflies, however, are known to cover long distances (e.g. Baldwin et al. 1975 ; Crosskey and Báez, 2004) and it is possible that the vectors disperse to Ile aux Aigrettes from the mainland as it is only $625 \mathrm{~m}$ offshore. Alternatively, Swinnerton et al. (2005) suggested that a different vector species may be transmitting $L$. marchouxi.

Blood parasites are assumed to exert costs on their hosts either directly, through nutrient competition or by forcing hosts to expend energy on immune function (Dawson and Bortolotti, 2000), or indirectly, by decreasing host foraging ability or increasing susceptibility to predation (Davidar and Morton, 1993). However, these costs are subtle and difficult to detect in wild avian populations (Bennett et al. 1988). Several studies have found a negative association between body condition and haematozoan infection status in wild birds (e.g. Dawson and Bortolotti, 2000; Merino et al. 2000), which is not evident in our study, but very few have demonstrated reduced survival of infected birds (but see Nordling et al. 1998; Stjernman et al. 2004). Leucocytozoon species are generally considered to be non-pathogenic in wild populations (Bennett et al. 1993; Hunter et al. 1997) and L. marchouxi has previously been recorded as pathogenic in the wild in only one other species: an Emerald-spotted Wood Dove Turtur chalcospilos in Zambia which was also co-infected with the potentially pathogenic haematozoan Haemoproteus columbae (Peirce, 1984). Thus, one notable finding of the present study is that Pink Pigeons infected with L. marchouxi showed significantly lower short-term (90 days postsampling) survival than uninfected birds. Whilst the difference in survival between infected and uninfected birds was significant to 90 days, it was not significant to 6 months or to 1 year. This result highlights the need to investigate post-sampling survivorship over different time-periods. One possible explanation for this apparent contradiction between short- and long-term survivorship differences of infected and uninfected birds is that seasonally latent haematozoan infections may be most pathogenic during the parasite's reproductive (patent) period. As mentioned above, our sampling targeted the months when both relapsed parasitaemias in previously infected individuals and new infections in juvenile birds were deemed most likely to be detected. It would be interesting to investigate whether the effect on short-term survivorship was a consequence of new parasitaemias in the cohort of susceptible young during these months. Age is likely to be a confounding factor in the survivorship analysis since juvenile survival tends to be lower than that of adults, and prevalence of $L$. marchouxi infection was highest in juveniles. Indeed, lower juvenile survival may be one cost of the latter. The effects of infection and age cannot be separated in this study due to the small sample size but research is continuing into this. Concomitant infections may 
also play a role. A host infected with one pathogen is likely to be more susceptible to infection with others and their combined effects may reduce survival. It would be possible to test this in the Pink Pigeons with larger samples of birds co-infected with $L$. marchouxi and T. gallinae. Unequivocal tests for harmful effects of parasitic infections on hosts would require experimental manipulations, which are fraught with difficulties in common species and are even more problematic, both practically and ethically, in endangered ones.

Demographic models suggest that parasites will be less enduring in small host populations (Dobson and May, 1991) but this is unlikely to be the case in the Pink Pigeon for several reasons. Many potential Columbid host reservoir species for L. marchouxi are widespread in Mauritius, including Madagascar Turtle-doves Streptopelia picturata, and introduced Spotted Doves Geopelia chinensis and Zebra Doves G. striata. When the Pink Pigeon population was very low, the parasite may have been maintained in these reservoir hosts but the current population size and high density of Pink Pigeons within each of the 5 subpopulations may favour maintenance and transmission of parasites. If $L$. marchouxi has been recently introduced to Mauritius, the Pink Pigeon may also lack the genetic resistance selected for in the parasite's natural host species. Leucocytozoonosis, in combination with other parasitic diseases, is therefore likely to be a persistent problem for the Pink Pigeon recovery programme.

It is surprising that no Plasmodium or Haemoproteus parasites have ever been detected in Pink Pigeon blood smears, particularly in light of both the comprehensive Pink Pigeon screening and the abundance of potential vectors-mosquitoes and hippoboscid flies respectively (N. Bunbury, personal observations) - at all sites. Both Plasmodium and Haemoproteus have been detected in other Mauritian birds, the latter in the Feral Pigeon Columba livia (Peirce et al. 1977) but neither appears to have successfully switched hosts to Pink Pigeons.

A frequent requirement in studies of avian haematozoa is that variation in parasite prevalence reflects the evolutionary background of hosts and parasites, since these studies often test theories that are dependent on such a relationship. Most tests of these theories have therefore concentrated on parasites in common species (e.g. Davidar and Morton, 1993) and, with the exception of the welldocumented and catastrophic introduction of avian malaria to the Hawaiian avifauna (Warner, 1968, van Riper et al. 1986), there is a paucity of published research into the effects of haematozoa in threatened host species in the wild, despite increasing recognition of the role that introduced parasites may play in the management of endangered species. The lack of known pathogenic effects of blood parasites in wild birds may reflect the fact that most research occurs on parasites in relatively common hosts. It is thus important to examine the effects of parasites in a range of host species, including endangered species in order to assess their full impact.

In conclusion, our study provides a measure of blood parasite prevalence in the entire free-living population of an endangered avian species within a 2 -month period. We showed considerable spatial variation in haematozoan prevalence, higher infection prevalence in juveniles and a significant negative correlation of Leucocytozoon infection with survival probability. Given the wealth of long-term life-history data available for the Pink Pigeon, the $L$. marchouxi-C. mayeri relationship is a valuable model in which to further investigate host-parasite systems in endangered birds.

The authors gratefully acknowledge the National Parks and Conservation Service for permission to work in the National Park and the Mauritian Wildlife Foundation for substantial logistic, financial and administrative help. We thank M. Peirce for his screening expertize and comments on the manuscript, R. Ashford, A. Cunningham, G. Valkiūnas, D. Wilkinson and two anonymous reviewers for valuable comments on the manuscript and D. Molyneux for identifying the trypanosome and helpful correspondence. We are grateful for financial support from the International Fund for Avian Research and Chester Zoo, and for help with fieldwork and screening from the MWF field staff, particularly N. Lohrmann and S. Sawmy. N. Bunbury was supported with a BBSRC Studentship (\# 01/ A1/S/07133) and E. Barton with a Wellcome Vacation Scholarship (\# VS/04/EAN/A1/OA/AM/FH).

\section{REFERENCES}

Allander, K. and Bennett, G. F. (1994). Prevalence and intensity of haematozoan infection in a population of great tits Parus major from Gotland, Sweden. Fournal of Avian Biology 25, 69-74.

Ashford, R. W., Wyllie, I. and Newton, I. (1990). Leucocytozoon toddi in British sparrowhawks Accipiter nisus: observations on the dynamics of infection. Fournal of Natural History 24, 1101-1107.

Atkinson, C. T. and van Riper III, C. (1991). Pathogenicity and epizootiology of avian haematozoa: Plasmodium, Leucocytozoon and Haemoproteus. In Bird-Parasite Interactions : Ecology, Evolution, and Behaviour (ed. Loye, J. E. and Zuk, M.), pp. 19-48. Oxford University Press, Oxford, UK.

Baldwin, W. F., Gomery, J. and West, A. S. (1975). Dispersal patterns of black flies (Diptera: Simuliidae) tagged with ${ }^{32} \mathrm{P}$. Canadian Entomology 107, 113-118.

Bennett, G. F., Caines, J. R. and Bishop, M. A. (1988). Influence of blood parasites on the body mass of passeriform birds. Fournal of Wildlife Diseases 24, 339-343.

Bennett, G. F., Peirce, M. A. and Ashford, R. W. (1993). Avian haematozoa: mortality and pathogenicity. Fournal of Natural History 27, 993-1001.

Crosskey, R. W. and Báez, M. (2004). A synopsis of present knowledge of the Simuliidae (Diptera) of the Canary Islands, including keys to the larval and pupal stages. Fournal of Natural History 38, 2085-2117. 
Daszak, P., Cunningham, A. A. and Hyatt, A. D. (2000). Emerging infectious diseases of wildlife: threats to biodiversity and human health. Science 287, 443-449.

Davidar, P. and Morton, E. S. (1993). Living with parasites: prevalence of a blood parasite and its effect on survivorship in the purple martin. Auk 110, 109-116.

Dawson, R. D. and Bortolotti, G. R. (1999). Prevalence and intensity of haematozoan infections in a population of American kestrels. Canadian Fournal of Zoology 77, 162-170.

Dawson, R. D. and Bortolotti, G. R. (2000). Effects of haematozoan parasites on condition and return rates of American kestrels. Auk 117, 373-380.

Deem, S., Karesh, W. B. and Weisman, W. (2001). Putting theory into practice: Wildlife health in conservation. Conservation Biology 15, 1224-1233.

Deviche, P., Greiner, E. C. and Manteca, X. (2001). Seasonal and age-related changes in blood parasite prevalence in Dark-eyed Juncos (Funco hyemalis, Aves, Passeriformes). Fournal of Experimental Zoology 289, 456-466.

Dobson, A. P. and May, R. M. (1991). Parasites, cuckoos and avian population dynamics. In Bird Population Studies: Relevance to Conservation Management (ed. Perrins, C. M., Lebreton, J.-D. and Hirons, G. J. M.), pp. 391-412. Oxford University Press, Oxford, UK.

Fallis, M. A. and Bennett, G. F. (1966). On the epizootiology of infections caused by Leucocytozoon simondi in Algonquin Park, Canada. Canadian Fournal of Zoology 44, 101-112.

Hamilton, W. D. and Zuk, M. (1982). Heritable true fitness and bright birds: a role for parasites? Science 218, 384-387.

Herman, C. M., Barrow, J. H. and Tarshis, I. B. (1970). Epizootiology of Leucocytozoon in Canada Geese (Branta canadensis). Fournal of Parasitology 56, 143-144.

Hunter, D. B., Rohner, C. and Currie, D. C. (1997). Mortality in great-horned owls from black fly hematophaga and leucocytozoonosis. Fournal of Wildlife Diseases 33, 486-491.

Kaplan, E. L. and Meier, P. (1958). Non-parametric estimation from incomplete observations. Fournal of American Statistics 53, 457-481.

Krone, O., Priemer, J., Streich, J., Sömmer, P., Langgemach, T. and Lessow, O. (2001). Haemosporidia of birds of prey and owls from Germany. Acta Protozoologica 40, 281-289.

McCallum, H. and Dobson, A. (1995). Detecting disease and parasite threats to endangered species and ecosystems. Trends in Ecology and Evolution 10, 190-194.

Merila, J., Bjorklund, M. and Bennett, G. F. (1995). Geographic and individual variation in haematozoan infections in the greenfinch Carduelis chloris. Canadian Fournal of Zoology 73, 1798-1804.

Merino, S., Moreno, J., Sanz, J. J. and Arriero, E. (2000). Are avian blood parasites pathogenic in the wild? A medication experiment in blue tits. Proceedings of the Royal Society of London, B 267, 2507-2510. DOI $10 \cdot 1098 / \mathrm{rspb} .2000 \cdot 1312$.

Nordling, D., Andersson, M., Zohari, S. and Gustafsson, L. (1998). Reproductive effort reduces specific immune response and parasite resistance. Proceedings of the Royal Society of London, B 267, 2507-2510.

Norris, K., Anwar, M. and Read, A. F. (1994). Reproductive effort influences the prevalence of haematozoan parasites in great tits. Fournal of Animal Ecology 63, 601-610.

Ots, I. and Hõrak, P. (1998). Health impact of blood parasites in breeding great tits. Oecologia 116, 441-448.

Peirce, M. A. (1984). Haematozoa of Zambian birds. I. General survey. Fournal of Natural History 18, 105-122.

Peirce, M. A., Cheke, A. S. and Cheke, R. A. (1977). A survey of blood parasites of birds in the Mascarene Islands, Indian Ocean. Ibis 119, 451-461.

Peirce, M. A., Greenwood, A. G. and Swinnerton, K. (1997). Pathogenicity of Leucocytozoon marchouxi in the Pink Pigeon (Columba mayeri) in Mauritius. Veterinary Record 140, 155-156.

Ricklefs, R. E. (1992). Embryonic development period and the prevalence of avian blood parasites. Proceedings of the National Academy of Sciences, USA 89, 4722-4725.

Rintamaki, P. T., Huhta, E., Jokimaki, J. and Squires-Parsons, D. (1999). Leucocytozoonosis and trypanosomiasis in redstarts in Finland. Fournal of Wildlife Diseases 35, 603-607.

Sanz, J. J., Arriero, E., Moreno, J. and Merino, S. (2001). Interactions between haemoparasite status and female age in the primary reproductive output of pied flycatchers. Oecologia 126, 339-344.

Schrader, M. S., Walters, E. L., James, F. C. and Greiner, E. C. (2003). Seasonal prevalence of a haematozoan parasite of red-bellied woodpeckers (Melanerpes carolinus) and its association with host condition and overwinter survival. Auk 120, 130-137.

Seutin, G. (1994). Plumage redness in redpoll finches does not reflect hemoparasitic infection. Oikos 70, 280-286.

Shutler, D., Ankney, C. D. and Dennis, D. G. (1996). Could the blood parasite Leucocytozoon deter mallard range expansion? Yournal of Wildlife Management 60, 569-580.

Sol, D., Jovani, R. and Torres, J. (2000). Geographical variation in blood parasites in feral pigeons: the role of vectors. Ecography 23, 307-314.

Sol, D., Jovani, R. and Torres, J. (2003). Parasitemediated mortality and host immune response explain age-related differences in blood parasitism in birds. Oecologia 135, 542-547.

Stjernman, M., Raberg, L. and Nilsson J.-A. (2004). Survival costs of reproduction in the blue tit (Parus caeruleus): a role for blood parasites? Proceedings of the Royal Society of London, B 271, 2387-2394. DOI 10.1098/rspb.2004.2883.

Swinnerton, K. J. (2001). Conservation and ecology of the Pink Pigeon Columba mayeri in Mauritius. Ph.D. thesis. Durrell Institute of Conservation and Ecology, University of Kent, Canterbury.

Swinnerton, K. J., Peirce, M. A., Greenwood, A. G., Chapman, R. E. and Jones, C. G. (2005). Prevalence of Leucocytozoon marchouxi in the endangered Pink Pigeon Columba mayeri. Ibis 147, 725-737. 
Tella, J. L. (2002). The evolutionary transition to coloniality promotes higher blood parasitism in birds. Fournal of Evolutionary Biology 15, 32-41.

Valkiūnas, G. (2005). Avian malaria parasites and other haemosporidia. CRC Press, Florida.

van Riper, C., van Riper, S. G., Goff, M. L. and

Laird, M. (1986). The epizootiology and ecological significance of malaria in Hawaiian land birds. Ecological Monographs 56, 327-344.
Warner, R. E. (1968). The role of introduced diseases in the extinction of the Hawaiian avifauna. Condor 70, 101-120.

Weatherhead, P. J. and Bennett, G. F. (1991). Ecology of red-winged blackbird parasitism by haematozoa. Canadian Fournal of Zoology 69, 2352-2359.

Weatherhead, P. J. and Bennett, G. F. (1992).

Ecology of parasitism of brown-headed cowbirds by haematozoa. Canadian Fournal of Zoology 70, 1-7. 